\title{
Gender and Cultural Aspects of Nutrition and Health - A Study in West Bengal
}

\author{
Dr. Purba Chattopadhyay ${ }^{1}$ \\ ${ }^{l}$ (Department of Home Science, Calcutta University, India)
}

\begin{abstract}
Nutrition is a concept essentially linked with access to food, utilisation of food and assimilation and retention through proper health and hygiene. Within this perspective, the present paper looks into the utilisation of food within a household where gender attitudes and self-esteem of 300 rural mothers from two districts of West Bengal were considered. The study looks into the impact of the above, on the nutrition and health security of 425 school going children from same socio-economic status, studying at primary level, in the age group of 5 to 12 years, under the ICDS midday meal scheme. The data was drawn by applying Clinical Nutrition Survey Chart; 24-hr recall method and Food Frequency Questionnaire, health and immunization records and expenditure on education, taking into consideration the gender of the child, birth order, and sex of the sibling. In this SPSS-17 was used for the descriptive statistics, t-test, $\chi 2$ for association and odd ratio calculation. It was seen that mothers with higher self-esteem had better gender attitudes at $0.05 \%$ level of significance. Further, it was seen that apart from gendered attitudes of the mothers, the cultural ethos related to the birth order of the child and the sex of its siblings are detrimental to the nutrition and health security of the girl child.
\end{abstract}

Keywords - Gender, Nutrition, Diet, Food Consumption, Health

\section{INTRODUCTION}

Food Security and nutrition being a multifaceted subject is linked directly to overall health scenario as they indicate the constituents of malnutrition that has far reaching consequences on the sustainable development, especially, in a developing country like India. Thus, in its basic form, food security is unwaveringly linked to nutritional security that implies physical, economic and social access to balanced diet, clean drinking water, safe environment, and health care (preventive and curative) for every individual. Looking at the seventh decade of independence, India as a country is yet to go beyond the stage of developmental transition, and still has to expend substantial resources in her ongoing battle with infectious diseases and consequences of under-nutrition. Not to forget that over 50\% of preschool children and 30\% of adults are undernourished, as judged by anthropometric indices, and over $70 \%$ of women and children suffer from anaemia. ${ }^{[1]}$ Added to this, the Census of India $2011^{[2]}$ reveals that the child sex ratio (number of girls per 1,000 boys among children in the age group $0-6$ years old) presently is at its lowest since India gained her independence. One of the most alarming trend that continue to sway India is that of adverse gender attitude towards girl child, which can be a normal attribute for household that manifests itself through neglect seen in lack of medical care, inadequate nutrition and even death through infanticide and feticide. Unfortunately, this is even evident among the educated and affluent classes in India. Sen $(1992,2003){ }^{[3]}$ first recognized that millions of women in India and China are missing because of widespread neglect in nutrition, health care, and prenatal care. India and China are the only countries in the world where female infant mortality rates are higher than that of males (United Nations, 2011) ${ }^{[4]}$.

A number of studies show intra household resource allocation focus on differences in entitlements of either women or children. Awasti $(1999,2003)^{[5][6]}$ have shown the poor status of children with regard to nutrition, and also reveals the gender aspect where girls fare worse than boys. Studies of Kapil U (1999) ${ }^{[7]}$, Preja N (2014) ${ }^{[8]}$ focused on the primary school going children and looked into their nutritional attainment found that the intake of micro nutrients of girls to be significantly lower than that of the boys. A study by Garg (1997) ${ }^{[9]}$ focussed on the nutritional intake of slum children exhibited similar results. Pande $\left(2003,2006\right.$, and 2007) ${ }^{[10]}[11]$ ${ }^{[12]}$ have shown that the neglect of children was directly correlated to their gender and their order of birth, and their likelihood of being immunised against disease or their likelihood of receiving a nutritious diet increased for boys than girls. Behram (1988) ${ }^{[13]}$ studied the Indian households and how boys were favoured to girls through differential attitudes of the parents. Tisdell (2000) ${ }^{[14]}$ in his study on rural Bengal on the intra household resource allocation reveal disparity in resource allocation with regard to gender. However, it was seen that the santhal families seem to perform well in comparison to the general population. In another study by Choudhary (2007) ${ }^{[15]}$ that dealt with the issue of work allocation within the family disclosed the role gender plays while deciding upon work allocation in the household. Studies by Falkner (1999) ${ }^{[16]}$ have shown the impact of malnutrition on the health of the children in form of stunting and wasting. Felson (1989) ${ }^{[17]}$ showed the impact 
of parental care on the self-esteem of the children. Some studies like by Mehrotra et al (2011) ${ }^{[18]}$ looked specifically into the role of midday meal (MDM) on educational attainment, and nutrition of primary school going children. Chattopadhyay (2016) ${ }^{[19]}$ looked into the impact of mother's self-esteem on the health and educational attainments of the tribal and non-tribal children of West Bengal.

One possible explanation of the discrepancy in child health or nutritional outcomes pertains to gender discrimination in the intra-household allocation of resources. Households are important decision-making units throughout the world. The dynamics and power play within the household has serious consequences on the wellbeing of not only the immediate members but also generations to come. The immediate consequence of gender dynamics within a household is perhaps best reflected towards the attitudes of the mothers who are the primary care giver towards their children. In this regard this study primarily concentrated on the gender attitudes of the mothers and their self-esteem and probed into the possible consequence of the same on variables like food intake, vaccination coverage, expenditure on education and access to formal health care facilities of the children belonging to a cross section of population from rural West Bengal. It also tries to look into the factors such as birth order and sex of the siblings in the health outcomes of the child in question.

1.1 Objectives:

a) To look into the gender attitudes and self-esteem of rural mothers.

b) To look into the impact of gender attitudes and self-esteem of rural mothers on the nutritional, health and educational entitlements of the children.

c) To look into the impact of order of birth and the gender of the siblings on the nutrition or health entitlement of the girl child.

2.1 Hypothesis

\section{MATERIALS AND METHOD}

H01: There is no significant correlation between mother's self-esteem and gender attitudes.

H02: There is no significant difference in nutrient intake of male and female children.

H04: There is no age wise association of for stunting for children of both gender.

H05: There is no age wise association for wasting for children of both gender.

H06: There is no significant difference in basic immunisation coverage of male and female children.

H07: There is no significant difference in access to formal health care services of male and female children.

H08: There is no significant difference in nutritional intake of the female child with respect to her birth order or the sex of her siblings.

H09: There is no significant difference in health entitlements of the female child with respect to her birth order or the sex of her siblings.

H10: There is no significant difference in stunting or wasting of the female child with respect to her birth order or the sex of her siblings.

2.2 Sample

The target population of this study was all the rural mothers in the age group 20 to 40 years having at least one primary school going children under the purview of ICDS midday meal scheme in West Bengal. The sample was drawn randomly by two stage sampling technique. 100 households from 3 villages of three districtsBirbhum and Purulia were selected with mothers in the age group 20 to 40 years. From these households 425 primary school going children were interviewed, among them 212 were boys and 213 were girls.

2.3 Tools

The tools used in the study were self-constructed gender attitude scales, having 15 questions which can be answered in yes and no, to measure the gender attitude of the mothers. The questions were validated through a pilot study. Test-retest reliability for it range from 0.79 to 0.81 and the criteria for validity is 0.59 . Rosenbergs (1965) self-esteem scale ${ }^{[20]}$ was used to measure the self-esteem of the mothers. It, comprised of 10 items, all the items were translated into Bengali and checked by two experts. The internal consistency for RSES range from 0.77 to 0.88 . Test-retest reliability for it range from 0.82 to 0.85 and the criteria for validity is 0.55 .

To assess the nutritional health status of the children 24-hr recall method, Food frequency questionnaire was used. In 24-hr recall method, the actual food and drink consumed in the immediate past 24 hours is recorded. Sometimes, a longer period may be used. The recorded food consumed in the last 24 hours is then converted to the nutrients available in each food item used in preparing it and then compared with the RDA ${ }^{[21]}$. Food Frequency Questionnaire was interviewer administered. A detailed questionnaire includes the list of foods and the subject answers as to how often and in what quantity each food is eaten per day, per week and per month. The collected information of the food consumed is then checked with the RDA. It gave an estimate of the amount and frequency of the various nutrients consumed by the individual. Further, follow-up's and cross checking were done with each household from which the child was coming. Anthropometric measures of 
children were collected regarding height and weight. Immunization records were verified and crosschecked from the mother who in most of the cases was the primary care giver.

2.4 Procedure

In this study, the method of two stage random sampling was used in collecting the data. The two villages were randomly selected from the cluster of villages from three districts of West Bengal. From each village 150 households with mothers in the age group of 20 to 40 years having at-least one primary school going child were selected randomly from the families. Socio economic background was controlled for the sample as all the children belonged to lower to middle economic strata. The exclusion principal was carried out with regards to below poverty line (BPL) families which were left out of the survey so as to get a clear picture on gender disparity as regards to nutritional and health outcomes if any of the afore mentioned sample. Also those mothers having children in the age higher or lower age group were excluded from the survey. Further the mothers of the children who were the primary care givers were comprehensively interviewed to look into their perceived gender outlook.

Table 1 The sample.

\begin{tabular}{|l|l|l|l|l|l|}
\hline & $\begin{array}{l}\text { Total Households (families with } \\
\text { small to medium land holdings } \\
\text { with married females in the age } \\
\text { group 20 to 40 years with primary } \\
\text { school going children) }\end{array}$ & $\begin{array}{l}\text { Household } \\
\text { interviewed }\end{array}$ & \multicolumn{3}{|c|}{ Children } \\
& & & \multicolumn{3}{|c|}{ Interviewed } \\
\cline { 4 - 8 } & & Boys & Girls & Total \\
\hline Village I & $1200(800)$ & 150 & 118 & 105 & 223 \\
\hline Village II & $1225(923)$ & 150 & 94 & 108 & 202 \\
\hline & Total & 300 & 212 & 213 & 425 \\
\hline
\end{tabular}

III. RESULTS AND DISCUSSION

The mean age of the women was $29.5 \pm 3.8$ (s.d) while the average years of education of the mothers were $17.96 \pm 2.1$ (s.d). The average monthly income of the families were Rs17107.65 \pm 408.51 (s.d).

A pilot study of the women of the households was first undertaken in one village to look into the gender outlook of the women (mothers). This is a crucial variable as it is the outlook of the mothers which would be detrimental to the food and basic resource entitlement of the children who are totally dependent on the primary care giver in the initial period of their lives. To access the mother's position in the household her autonomy to take decisions and command over the resources were also questioned. This was then extended to the other two villages

Table 2 Gender outlook of rural mothers

\begin{tabular}{|c|c|c|c|c|c|c|}
\hline & $\begin{array}{l}\text { Mean } \\
\text { Scores }\end{array}$ & S.D & $\mathrm{t}_{\mathrm{cal}}$ & $\mathrm{t}_{\mathrm{tab}}$ & Conclusion & \\
\hline $\begin{array}{l}\text { Mothers with at most } \\
\text { one girl child }\end{array}$ & 39.07 & 1.28 & 19.34 & $1.62^{*}$ & $\begin{array}{ll}\mathrm{t}_{\text {cal }>} \mathrm{t}_{\mathrm{tab}} & \text { Null } \\
\text { rejected } & \end{array}$ & Hypothesis \\
\hline $\begin{array}{l}\text { Mothers with two or } \\
\text { more girl child }\end{array}$ & 17.86 & 1.76 & & & & \\
\hline
\end{tabular}

The gender outlook scores of the mothers with boy child or with at most one girl child are significantly different than the mothers with two or more girl child so the null hypothesis is rejected and alternative hypothesis accepted. It can be seen that gender discrimination was less visible in families with one girl child than that for families with more than two girl child. Thus, the gender outlook of the prime care giver of the children varied with the sex of the child. Next the self -esteem scores were calculated using the Rosenberg's SES. In this scale higher scores indicate higher self-esteem.

Table 3 Self-esteem of rural mothers- with one to two girl child and three or more girl child

\begin{tabular}{|l|l|l|l|l|l|}
\hline & Mean Scores & S.D & $\mathrm{t}_{\text {cal }}$ & $\mathrm{t}_{\text {tab }}$ & Conclusion \\
\hline Mothers with at most one girl & 29.8 & 1.2 & 74.34 & $1.6552^{*}$ & $\mathrm{t}_{\mathrm{cal}} \mathrm{t}_{\mathrm{tab} ;}$ Null \\
\hline
\end{tabular}




\begin{tabular}{|l|l|l|l|l|l|}
\hline child & & & & & $\begin{array}{l}\text { Hypothesis } \\
\text { rejected }\end{array}$ \\
\cline { 1 - 1 } \\
$\begin{array}{l}\text { Mothers with two or more girl } \\
\text { child }\end{array}$ & 10.5 & 1.8 & & & \\
\hline
\end{tabular}

Relatively higher self-esteem was seen among women in families with lesser number of girl child. From the Table 3 it can be concluded that there is significant difference in the self-esteem scores of the women with at most one girl child hence the null hypothesis is rejected and alternative hypothesis accepted at $0.05 \%$ level of significance. Further it was found that that positive nondiscriminatory gender attitudes were positively correlated to the self-esteem scores $(\mathrm{r}=+0.79)$ at $\mathrm{p}=0.05$.

Next we try to look into the nutritional, health and educational entitlements of the primary school going children of the mothers discussed above using 24 hour recall method.

Table -4 Percentage distribution of children according to deficient nutrient intake within last 24 hours (Children 5-12 years)

\begin{tabular}{|l|l|l|l|}
\hline \multirow{2}{*}{$\begin{array}{l}\text { Nutrients } \\
\text { Groups }\end{array}$} & RDA & \multicolumn{2}{l|}{$\begin{array}{l}\text { test for difference in means between boys and girls at } \\
5 \% \text { level of significance }\end{array}$} \\
\cline { 3 - 4 } & & $\mathrm{t}$-value & Significance \\
\hline Protein(g/day) & 41 & $2.89^{*}$ & $\mathrm{~S}\left(\mathrm{t}_{\text {cal }}>\mathrm{t}_{\text {tab }}\right)$ \\
\hline Fat & 25 & $1.05^{*}$ & $\mathrm{NS}$ \\
\hline Carbohydrates & 390 & $0.98^{*}$ & $\mathrm{NS}$ \\
\hline Energy & 1950 & $1.06^{*}$ & $\mathrm{NS}$ \\
\hline Calcium & 400 & $3.08^{*}$ & $\mathrm{~S}\left(\mathrm{t}_{\text {cal }}>\mathrm{t}_{\text {tab }}\right)$ \\
\hline Iron & 26 & $\mathrm{NS}$ \\
$* \mathrm{p}=0.05, \mathrm{NS}=$ Non Significant, $\mathrm{S}=$ Significant & $1.06^{*}$
\end{tabular}

From the above table it can be seen that with regard to the difference between the nutrient intakes in most of the cases there is no significant difference between each nutrient groups for both boys and girls, for both groups. However for families with more than two girl child, we can see that there lies a significant difference between boys and girls for protein and calcium intake. Reported discrimination was evident when particular food like fish, meat or milk were considered. The care givers were directly practicing discrimination regards to certain food groups. Also, it should be noted that in the above sample no child reported of hunger as such especially carbohydrate intake was sufficient for all the children due to the provision of food in the schools through midday meal scheme. Only the mothers are practicing discriminatory behaviour but also they consider it to be justifiable. Thus, a mere increase in income is not ensuring the well-being for a group of children. In most of the families with two or more girl child the mother supplements the boy's meal by providing milk or protein rich items like fish or poultry. To have a better look into the intra household gender dynamics we look into the likelihood of being micronutrient deficient based on the birth order of the girl child as well the gender of her siblings.

Table 5 Odd Ratio calculation for girl child for micronutrient deficiency based on the birth order

\begin{tabular}{|l|l|l|}
\hline Birth order & Deficient & No deficiency \\
\hline $1^{\text {st }}$ or $2^{\text {nd }}$ born & $0.47^{*}$ & $0.58^{*}$ \\
\hline $3^{\text {rd }}$ or more & $1.86^{*}$ & $0.76^{*}$ \\
\hline \multicolumn{2}{l}{${ }^{*}=0.05$}
\end{tabular}

Table 6 Odd Ratio calculation for girl child for micronutrient deficiency based on the sex of her siblings

\begin{tabular}{|l|l|l|}
\hline Sex of siblings & Deficient & No deficiency \\
\hline At least one brother & $0.52^{*}$ & $0.78^{*}$ \\
\hline No brother & $1.09^{*}$ & $0.86^{*}$ \\
\hline \multicolumn{2}{l}{${ }^{\mathrm{p}}=0.05$} &
\end{tabular}

Thus to have a closer look into the micronutrient deficiency of the girl child we disaggregate the data based on the order of her birth and the sex of her siblings respectively as shown in table 5 and 6 . It can be seen that the probability of being micronutrient deficient increases for a girl child if she is third or more born or has no brother. The worst victim of micronutrient deficiency is observed in case of girl child who are further down the birth order with same sex siblings. This is a disturbing fact as it has nothing to do with the availability of 
resources within the household and it is the socio-cultural aspects of life which becomes detrimental to the nutritional intake of the girl child.Next, we will look into the effect of undernourishment in form of stunting and wasting.

Table 7 Distribution of Stunting (Height for age)

\begin{tabular}{|c|c|c|c|c|}
\hline \multirow{2}{*}{$\begin{array}{l}\text { Age } \\
\text { (in } \\
\text { years) }\end{array}$} & \multicolumn{2}{|c|}{$\chi^{2}$ for age wise association for stunting } & \multicolumn{2}{|c|}{$\begin{array}{l}\mathrm{t} \text {-test for significant difference between } \\
\text { boys and girls at } 5 \% \text { level }\end{array}$} \\
\hline & $\chi^{2}$-value & Significance & t-value & Significance \\
\hline $5-8$ & $2.89^{*}$ & NS & $2.65^{*}$ & NS \\
\hline $8-12$ & $4.02^{*}$ & $\mathrm{~S}\left(\mathrm{t}_{\mathrm{cal}}>\mathrm{t}_{\mathrm{tab}}\right)$ & $5.86^{*}$ & $\mathrm{~S}\left(\mathrm{t}_{\mathrm{cal}}>\mathrm{t}_{\mathrm{tab}}\right)$ \\
\hline
\end{tabular}

Data (Table 7) reveals that moderate to severe stunting exists in all age groups as well as for both the groups of children. However no significant association was found between the age groups and stunting for children aged 5-8years. However, for the higher age group the difference is significant. To look have a detailed view on stunting of the girl child we again look into the disaggregated data based on birth order and sex of siblings of the girl child.

Table 8 Odd Ratio calculation for girl child for stunting at 95\% level of significance (0-12years) based on the birth order

\begin{tabular}{|l|l|l|}
\hline Birth order & Severely Stunted & Normal \\
\hline $1^{\text {st }}$ or $2^{\text {nd }}$ born & $0.62^{*}$ & $0.78^{*}$ \\
\hline $3^{\text {rd }}$ or more & $1.86^{*}$ & $0.76^{*}$ \\
\hline \multicolumn{2}{|l}{${ }^{*} \mathrm{p}=0.05$, NS=Non Significant, S=Significant } \\
\hline
\end{tabular}

Table 9 Odd Ratio calculation for girl child for stunting at $95 \%$ level of significance (0-12years) based on the sex of the siblings

\begin{tabular}{|l|l|l|}
\hline Sex of siblings & Severely Stunted & Normal \\
\hline At least one brother & $0.45^{*}$ & $0.80^{*}$ \\
\hline No brother & $1.99^{*}$ & $0.97^{*}$ \\
\hline
\end{tabular}

* $\mathrm{p}=0.05, \mathrm{NS}=$ Non Significant, $\mathrm{S}=$ Significant

As is seen from Table 8 and 9 , the probability of being severely stunted for a girl child increases if she has no brother and / or is third or more in the order of birth. These result are directly in consequence of the results on micro nutrient deficiencies which reinforces the fact that the birth order and the sex of the siblings of the girl child are directly consequential to her well-being. Next we look into the wasting as observed in the sample.

Table 10 Distribution of wasting (weight for age)

\begin{tabular}{|l|l|l|l|l|}
\hline $\begin{array}{l}\text { Age (in } \\
\text { years) }\end{array}$ & \multicolumn{2}{|l|}{$\chi 2$ for age wise association for wasting } & $\begin{array}{l}\text { t-test for significant difference between } \\
\text { boys and girls at 5\% level }\end{array}$ \\
\cline { 2 - 5 } & $\chi 2$-value & Significance & t-test value & Significance \\
\hline $5-8$ & $2.09^{*}$ & $\mathrm{NS}$ & $1.08^{*}$ & $\mathrm{NS}$ \\
\hline $8-12$ & $5.99^{*}$ & $\mathrm{~S}\left(\mathrm{t}_{\mathrm{cal}} \mathrm{t}_{\mathrm{tab}}\right)$ & $8.43^{*}$ & $\mathrm{~S}\left(\mathrm{t}_{\text {cal }} \mathrm{t}_{\text {tab }}\right)$ \\
\hline
\end{tabular}

Data reveals that moderate to severe wasting exists in all age groups as well as for both the groups of children. However, no significant association was found between the age groups and stunting for the lower age group. The plausible explanation of such insignificant result is that the effects of micronutrient deficiencies manifests itself in the teens and adolescent period. Which is manifested in the older age groups where the difference between the girl and the boys are significant as regards to wasting. Looking into the problem of wasting at the disaggregated level we calculate the odd ratios for wasting in case of the girl child.

Table 11 Odd Ratio calculation for girl child for wasting at 95\% level of significance (0-12years) based on the birth order

\begin{tabular}{|l|l|l|}
\hline Birth order & Severely Wasted & Normal \\
\hline $1^{\text {st }}$ or $2^{\text {nd }}$ born & $0.47^{*}$ & $0.78^{*}$ \\
\hline
\end{tabular}




\begin{tabular}{|c|l|l|}
\hline $3^{\text {rd }}$ or more & $1.46^{*}$ & $0.86^{*}$ \\
\hline${ }^{*} \mathrm{p}=0.05$ &
\end{tabular}

Table 12 Odd Ratio calculation for girl child for wasting at $95 \%$ level of significance (0-12years) based on the sex of the siblings

\begin{tabular}{|l|l|l|}
\hline Sex of siblings & Severely Wasted & Normal \\
\hline At least one brother & $0.62^{*}$ & $0.58^{*}$ \\
\hline No brother & $1.07^{*}$ & $0.66^{*}$ \\
\hline
\end{tabular}
$* \mathrm{p}=0.05$

Both the Tables-11 and 12 reveal that the chances of being severely wasted increases if the girl child is lower down the birth order with no brothers as siblings.

Next we look into the basic health provisioning through looking into the immunization coverage of both the groups.

Table 13 Odd Ratio calculation for both sexes for immunization coverage at $95 \%$ level of significance \{Vaccination Coverage (0-6months) \}

\begin{tabular}{|l|l|l|}
\hline Gender & Families with two or more girl child & $\begin{array}{l}\text { Families with at most one } \\
\text { girl child }\end{array}$ \\
\hline Boys & $0.35^{*}$ & $0.30^{*}$ \\
\hline Girls & $0.58^{*}$ & $0.38^{*}$ \\
\hline
\end{tabular}

In case of odd ratio calculation for vaccination coverage for 0 to 2 years we can see that irrespective of the fact that to which family the child comes from- whether he or she is from family with two or more girl child or from family with at most one girl child the probability of getting vaccinated is high for both groups irrespective of the gender of the child.

Table 14 Odd Ratio calculation for both sexes for immunization coverage at $5 \%$ level of significance \{Vaccination Coverage (Above 2 years and booster dosage)

\begin{tabular}{|l|l|l|}
\hline Gender & $\begin{array}{l}\text { Families with two or more girl } \\
\text { child (immunization coverage) }\end{array}$ & $\begin{array}{l}\text { Families with at most one girl } \\
\text { child(immunization coverage) }\end{array}$ \\
\hline Boys & $0.62^{*}$ & $0.91^{*}$ \\
\hline Girls & $1.89^{*}$ & $0.97^{*}$ \\
\hline \multicolumn{2}{|l}{$\mathrm{p}=0.05$}
\end{tabular}

In case of odd ratio calculation for follow-up vaccination and booster dosage we can see that for families with at most one girl child the probability of getting vaccinated is high irrespective of the gender of the child. This accrues to lack of awareness and education in general. However for families with two or more girl child, the probability of getting vaccinated increases if the child is a boy rather than a girl. Again, looking into the disaggregated data for immunization coverage for the girl child we see that the gender of her siblings as well as her own birth order acts as crucial factors for the immunisation of the girl child.

Table 15 Odd Ratio calculation for girl child for immunization coverage at $95 \%$ level of significance ( 0 -

12 years) based on the birth order

\begin{tabular}{|l|l|l|}
\hline Birth order & Poor Coverage & Good Coverage \\
\hline $1^{\text {st }}$ or $2^{\text {nd }}$ born & $0.44^{*}$ & $0.81^{*}$ \\
\hline $3^{\text {rd }}$ or more & $1.76^{*}$ & $0.95^{*}$ \\
\hline${ }^{*} \mathrm{p}=0.05$ &
\end{tabular}

Table 16 Odd Ratio calculation for girl child for immunization coverage at $95 \%$ level of significance $(0$ 12 years) based on the sex of the siblings

\begin{tabular}{|l|l|l|}
\hline Sex of siblings & Poor Coverage & Good Coverage \\
\hline At least one brother & $0.48^{*}$ & $0.82^{*}$ \\
\hline No brother & $1.93^{*}$ & $0.96^{*}$ \\
\hline \multicolumn{2}{|l}{$\mathrm{p}=0.05$} &
\end{tabular}

Thus, as can be seen from the above Tables 15 and 16 we see that the probability of not getting immunised increases if the girl child comes late in the order of birth and has siblings of the same sex. Lastly, we take a look into the accessibility of formal health care of the children by looking into the data on hospitalization or formal prescription in case of incidence of common ailments like fever or diarrhoea. 
Table 17 Odd Ratio calculation for both sexes for hospitalization in case of fever or diarrhea at $95 \%$ level of significance (0-12years)

\begin{tabular}{|l|l|l|}
\hline Gender & $\begin{array}{l}\text { Families with two or more girl child } \\
\text { (Access to formal health care) }\end{array}$ & $\begin{array}{l}\text { Families with at most one girl } \\
\text { child(Access to formal health care) }\end{array}$ \\
\hline Boys & $0.48^{*}$ & $0.86^{*}$ \\
\hline Girls & $1.76^{*}$ & $0.86^{*}$ \\
\hline
\end{tabular}

In case of odd ratio calculation for hospital care or visiting doctors we can see that for families with at most one girl child are faring better than those with at least two or more girl child.

Table 18 Odd Ratio calculation for girl child for hospitalization in case of fever or diarrhea at $95 \%$ level of significance (0-12years) based on the birth order

\begin{tabular}{|l|l|l|}
\hline Birth order & Not Hospitalized(or Formal Care) & Hospitalized \\
\hline $1^{\text {st }}$ or $2^{\text {nd }}$ born & $0.44^{*}$ & $0.82^{*}$ \\
\hline $3^{\text {rd }}$ or more & $1.95^{*}$ & $0.91^{*}$ \\
\hline \multicolumn{2}{|l}{${ }^{*} \mathrm{p}=0.05$} &
\end{tabular}

Table 19 Odd Ratio calculation for girl child for hospitalization in case of fever or diarrhea at $95 \%$ level of significance (0-12years) based on the sex of the siblings.

\begin{tabular}{|l|l|l|}
\hline Sex of siblings & Not Hospitalized(or Formal Care) & Hospitalized \\
\hline At least one brother & $0.45^{*}$ & $0.83^{*}$ \\
\hline No brother & $1.97^{*}$ & $0.90^{*}$ \\
\hline \multicolumn{2}{|l}{$\mathrm{p}=0.05$} &
\end{tabular}

Looking into the disaggregated data on the girl child, in Table 18 and 19, we see that the probability of getting formal health care for a girl child increases if she is a first or second born or has brothers as siblings.

Thus, the above study shows that there are certainly some strong attitudinal, social and cultural practices not necessarily economic in nature which have a profound impact on the behaviour of the rural mothers having primary school going children regarding gender. The self-esteem and the gender outlook of these rural mothers get reflected in their conduct towards their children depending upon the sex of the child. Further, apart from the gender of the child it is the birth order or the sex of the siblings which are consequential to the food and health entitlement of the primary school goer.

The study showed that

\section{CONCLUSION}

- Women are the primary care givers in the household.

- There is significant correlation between gender attitudes and self-esteem of rural mothers

- Due to gendered inequity and exclusion, health and nutrition of generations to come gets jeopardized and thus their children especially girls become more vulnerable than boys.

- The likelihood of being micronutrient deficient increases if the child is a girl.

- The likelihood of being vaccinated, taken proper care of in case of diseases increases if the child is a boy.

- The likelihood of being stunted, wasted or being micronutrient deficient increases for a girl child if she has two or more siblings of the same sex.

- The likelihood of being stunted wasted or being micronutrient deficient increases if the child is a girl child who is third or more in the birth order.

- The likelihood of being immunized and taken proper care of in case of diseases decreases if a girl child has two or more siblings of the same sex or is third or more in the order of birth.

4.1 Shortcomings

This study can be further extended across various class and caste of the society. Religion could also be included and ANNOVA could be performed to see the variances across the various groups.

4.2 Recommendation

While devising policies to tackle malnutrition, the outlook and attitudes of the people in question should be taken into account. Government intervention in case of primary vaccination has been successful in counter balancing the gendered skewness. Similarly for specific micro nutrient intervention in the diet of the primary school goer may have significant positive impact on the health of the child, and will reduce the gendered negativity, as practiced within the households. 


\section{REFERENCES}

[1] UNFPA data (Dec, 2014). Retrieved from https://www.unfpa.org/sites/default/files/resourcepdf/UNFPA_Publication-39764.pdf

[2] Census data (16 June, 2014) http://www.census2011.co.in/

[3] Sen, A. Gender and Cooperative Conflicts, Persistent Inequalities, Tinker, I. (ed.) (New Delhi: Oxford University Press, 1990).

[4] Sen, A. The Many Faces of Gender Inequality, Retrieved from http://prof.chicanas.com/readings/SenInequality.pdf (2001).

[5] UNDP Report Retrieved from http://hdr.undp.org/sites/default/files/reports/271/hdr_2011_en_complete.pdf (2011).

[6] Awasthi, N. \& Kumar, A. R. Nutritional status of hill primary school children. The Indian Journal of Nutrition and Dietetics, 36, 1999, 453- 460.

[7] Awasthi, S., Das, R., Verma, T., \& Vir, S. Anaemia and under nutrition among pre-school children in Uttar Pradesh, India. Indian Paediatrics, 40 (10), 2003, 985-990.

[8] Kapil, U. \& Pradhan, R. Integrated Child Development Services scheme (ICDS) and its impact on nutritional status of children in India and recent initiatives. Indian Journal of Public Health, 43 (1), 1999, 21-5.

[9] Preja, N. To Assess the Nutritional Status of the Midday meal consuming rural School Going Girls (7-10 years). International Journal of Engineering Science Invention, 3(3), 2014, 6719 - 6726

[10] Garg, S.K., Singh, J.V., Bhatnagar, M. \& Chopra, H. Nutritional status of children (1-6 years) in slums of Ghaziabad city, Indian Journal of Community Medicine, 22(2), 1997, 70-73.

[11] Pande, R. P. Selective Gender Differentials in Childhood Nutrition and Immunization in Rural India: The Role of Siblings. Demography. 40(3), 2003, 395-418.

[12] Pande, R.P. \& Nan, M. A. Explaining son preference in rural India: The independent role of structural versus individual factors. Population Research and Policy Review, 26(3), 2007, 14-18.

[13] Behrman, J.R. Intrahousehold Allocation of Nutrients in Rural India: Are Boys Favored? Do Parents Exhibit Inequality Aversion? Oxford Economic Papers, 40(1), 1988, 32-54

[14] Tisdell, C. Gender inequality in India: evidence from a rural survey in West Bengal Social Economics Policy and Development, Working Paper, 13, 2000.

[15] Choudhary, N. \& Parthasarathy, D. Gender, Work and Household Food Security, Economic and Political Weekly, 42 (6), 2007, 523-531

[16] Falkner, F. Malnutrition and growth. Child Health, 11, 1991, 8-11.

[17] Felson, R.B. \& Zielinski, M.A. Children's Self-Esteem and Parental Support. Journal of Marriage and Family. 51(3), 1989, 727-735

[18] Mehrotra, M., Arora, S. \& Nagar, V., 2014, Retrieved from http://mdm.nic.in/Files/Initiatives\%20\&\%20Case\%20Studies/Nutritional_Health.pdf

[19] Chattopadhyay, P. Impact of Mothers Self Esteem and Attitude Towards Gender on the Nutritional and Health Entitlements of the Primary School Going Children -A Study in West Bengal, International Journal Of Home Science, 2(2), 2016, 171-176

[20] Rosenberg, A. (23may, 2014) Retrieved from www.statisticssolutions.com/rosenberg-self-esteem-scale-ses/

[21] ICMR. Nutrient requirement and RDA for Indians. Hyderabad: National Institute of Nutrition, $1990,83$. 